\title{
Anomaly Nesting: A Methodology to Downscale Seasonal Climate Simulations from AGCMs
}

\author{
VASUBANDHU MisRA \\ Center for Ocean-Land-Atmosphere Studies, Institute of Global Environment and Society, Inc., Calverton, Maryland \\ MASAO KANAMITSU \\ Experimental Climate Prediction Center, University of California, San Diego, La Jolla, California
}

(Manuscript received 7 May 2003, in final form 23 February 2004)

ABSTRACT

\begin{abstract}
In this paper a methodology is proposed to downscale coarse-resolution atmospheric general circulation model (AGCM) seasonal simulations. Anomaly nesting involves replacing the climatology of the driving AGCM with observed (in this case the National Centers for Environmental Prediction reanalysis) climatology at the lateral boundaries of the nested regional climate model (the regional spectral model). In this study the methodology is tested over South America and the neighboring ocean basins. A comparison of the austral summer seasonal simulation with the conventional way of nesting, namely driving the regional model with full AGCM forcing, reveals that substantial gains in the deterministic skill are realized through anomaly nesting. It is also shown that the high-frequency variance (at 3-30- and 30-40-day time scales) is more realistic from the anomaly nesting procedure.
\end{abstract}

\section{Introduction}

The concept of anomaly nesting as a methodology to downscale atmospheric general circulation model (AGCM) climate simulations is inspired from a growing skepticism in the regional modeling community on the efficacy of improving seasonal forecasts from regional climate models (RCMs) over those from AGCMs. Some recent regional climate modeling studies (Misra et al. 2003; Altshuler et al. 2002) emphasize that the regional models carry the pathological errors forced by the driving AGCM through the lateral boundary conditions, thereby limiting the usefulness of the higher-resolution simulations from the RCM at these time scales. This follows from the earlier studies of Noguer et al. (1998), Risbey and Stone (1996), and Denis et al. (2002), which indicate that an RCM cannot be expected to improve the finescale if the driving AGCM provides poor lateral boundary conditions. Roads and Chen (2000) found that in comparison to large-scale observations, regional models did not offer any obvious advantage over the coarser AGCM. More recently, Roads et al. (2003) found that higher-resolution regional model climate sim-

Corresponding author address: Vasubandu Misra, Center for Ocean-Land-Atmosphere Studies, Institute of Global Environment and Society, Inc., 4041 Powder Mill Rd., Suite 302, Calverton, MD 20705.

E-mail: misra@cola.iges.org ulations over the continental United States did not improve the skill of the temporal variability over that of the driving AGCM. However, the topographically forced features of the seasonal climate were better depicted in the regional model simulation. In another related study, Pan et al. (2001) noted that the differences between the RCM integrations over the continental United States forced with an AGCM and the National Centers for Environmental Prediction (NCEP) reanalysis are largest in the summer season owing to the sensitivity of the convective parameterization to subtle changes in the forcing. Noguer et al. (1998) also show that an AGCM forced RCM simulation had large errors which was related to the systematic errors of the AGCM. This error in their study was significantly reduced when they forced the RCM with an AGCM that had relatively far less of the systematic errors (which was achieved by strongly relaxing the AGCM simulation to the operational analysis). Druyan et al. (2002) compared two RCM simulations over South America, one forced by National Centers for Environmental Prediction reanalysis and the other forced by an AGCM. They found that from the former configuration the skill of the downscaled seasonal precipitation was far better than from the latter setup.

But there are studies which indicate that the influence of the driving AGCM on the nested RCM is diminished under certain conditions. Jones et al. (1995) using sev- 
eral nested regional models with different domain sizes over Europe found that the mean flow and synopticscale variability of the RCM integrations with larger domains diverged from that of the driving AGCM. Furthermore, in the RCM integrations with a relatively smaller domain, the synoptic circulation closely followed the driving AGCM forcing. Noguer et al. (1998) find that the RCM simulation is less influenced by the systematic errors of the driving AGCM relative to the internal physics especially during the summer season and for some of the surface forced fields such as precipitation and surface air temperature. In an extensive intercomparison project of regional climate simulation over the continental United States, Takle et al. (1999) found that most models are able to uniformly reproduce the large-scale features and synoptic-scale variability forced by a ridge or zonal flow, while periods affected by short-wave lows or troughs tend to have larger intramodel variance. In a similar vein, they find that precipitation episodes from organized synoptic-scale systems are predicted by most models while mesoscale and convective precipitation are represented in a stochastic sense.

From the aforementioned discussion it can be noted that the influence of the lateral boundary conditions on the evolving climate in an RCM is influenced by the size of the regional domain, season of the year, the region, the RCM physics and dynamics, and the variable in question.

The concept of anomaly nesting is simple. In this approach the idea is to provide the nested RCM in an AGCM with lateral boundary conditions bereft of the drift of the AGCM, by replacing its climatology with the observed (analyzed) climatology. There are obviously certain disadvantages with this method. The foremost is that the AGCM climatology would have to be generated afresh any time changes are made to the AGCM, either in its components (physics or dynamics) or in spatial resolution. In addition, the quality of the new lateral boundary conditions is limited by the quality of the observed or analyzed climatology used in replacing the AGCM climatology. It also introduces a dynamical imbalance to the lateral boundary forcing because the nonlinear terms are not necessarily additive. Notwithstanding these limitations, this methodology provides a unique way of determining the role of largescale climate drift on the regional climate and its variability. It should be noted that such a concept has already been adopted in coupled ocean-atmosphere models (Kirtman et al. 2002).

For this study we have chosen our regional domain over South America simply because we have the baseline experiments from an earlier study (Misra et al. 2002, 2003). However, South America as a region also offers a unique setting to understand predictability, with its steep Andes mountains on the western edge and the associated variability of the two neighboring major tropical basins of the Pacific and Atlantic Oceans.
In the following section we shall provide the details of the RCM and AGCM used in this study, followed by the description of the nesting methodology. The results are discussed in section 4 along with concluding remarks in section 5 .

\section{Model description}

In this section we shall briefly describe the AGCM and the RCM used in this study.

\section{a. The AGCM}

The AGCM used in this study is version 2.2 of the Center for Ocean-Land-Atmosphere Studies (COLA) global spectral model at $\mathrm{T} 42\left(2.5^{\circ}\right)$ horizontal resolution and 18 vertical levels of the terrain-following sigma coordinate system. This version of the model uses the dynamical core of the National Center for Atmospheric Research Climate Community Model version 3 (CCM3) described in Kiehl et al. (1998). The dependent variables of the model are spectrally treated except for the moisture variable which is advected using the semi-Lagrangian technique. The parameterization of deep convection follows the relaxed Arakawa-Schubert scheme (Moorthi and Suarez 1992). The parameterization of shallow convection follows Tiedtke (1984). The subgrid-scale exchange of heat, momentum, and moisture is accomplished via a turbulent closure scheme, level 2.0 (Mellor and Yamada 1982). The diagnostic cloud fraction and optical properties are similar to CCM3 (Kiehl et al. 1998) and are described in Dewitt and Schneider (1997). The terrestrial and shortwave radiation follows Harshvardhan et al. (1987) and Davies (1982), respectively. A fourth-order horizontal diffusion is applied to all variables except the moisture variable. A mean surface orography (Fennessy et al. 1994) is used to represent surface elevation. Dry convective adjustment and gravity wave drag are not invoked in the model integrations. The atmospheric model is coupled to the Simplified Simple Biosphere model documented in Xue et al. (1991, 1996) and Dirmeyer and Zeng (1997).

\section{b. The RCM}

For this study we have adopted the regional spectral model (RSM) following Juang and Kanamitsu (1994) and Juang et al. (1997) as our RCM. The RSM predicts the total field of divergence $(\chi)$, vorticity $(\zeta)$, temperature $(T)$, natural $\log$ of surface pressure $\left(\ln p_{s}\right)$, and specific humidity $(q)$. Since it is not mathematically possible to explicitly compute nonlinear perturbation tendency from perturbation and base field (particularly for physical processes), the model computes tendencies from the full field and subsequently the perturbation tendency is computed as a difference between this tendency and the known base field tendency and then Fourier filtered. This method should be considered optimum 
perturbation filtering, rather than the perturbation prediction. In principle, this method can easily be applied to conventional regional gridpoint models. The RSM uses the terrain-following vertical coordinate system. The model equations are integrated by a semi-implicit scheme while the moisture and vorticity equation are integrated explicitly.

The model has a comprehensive physics package that includes shortwave (Chou 1992) and longwave (Fels and Schwarzkopf 1975) radiation which are fully interactive with the clouds. The boundary layer physics in the model employs a nonlocal diffusion scheme developed by Hong and Pan (1996) which is strongly coupled to the surface-layer physics. The flux computations in the surface layer are based on Monin-Obukhov similarity theory. The model also includes the Simplified Simple Biosphere (SSiB) scheme following Xue et al. (1991, 1996) which is identical to that in the COLA AGCM. The deep convection is parameterized with a simplified Arakawa-Schubert (SAS) scheme (Pan and $\mathrm{Wu}$ 1995). The large-scale condensation (and re-evaporation) involves disposition of supersaturation. Shallow convection following Tiedtke (1984) is invoked only in the absence of deep convection. The gravity wave drag formulation of Alpert et al. (1988) is also included.

In this study the RSM is at an $80-\mathrm{km}$ grid resolution with dimensions of 217 (zonal) $\times 112$ (meridional) centered at $15^{\circ} \mathrm{S}$ and $80^{\circ} \mathrm{W}$. The time step of the integration is $240 \mathrm{~s}$. The base field is linearly interpolated in time and bicubic spline interpolated in space to the RSM grid.

\section{The anomaly nesting procedure}

In this study, the RSM is nested into the AGCM with a nesting period of $12 \mathrm{~h}$. The nested variables of RSM are $\lambda, \zeta, T, \ln p_{s}$, and $q$. First, an AGCM climatology for every $12-\mathrm{h}$ period of the Julian day during the season is generated. For this study the start and end dates for all model integrations are from 0000 UTC 15 December to 1200 UTC 31 March of the following year. Therefore, to generate the AGCM climatology we integrated the AGCM for a season between the dates just mentioned for the years from 1984 to 1995 with the model output stored at intervals of $12 \mathrm{~h}$. For each of the years, fivemember AGCM ensemble integrations were made and the climatology was generated from the ensemble mean.

To generate the corresponding observed climatology we used the NCEP reanalysis available on $2.5^{\circ}$ latitudelongitude grid on 17 mandatory pressure levels. The NCEP reanalysis climatology was then generated at T42 spectral truncation from this dataset and at exactly the same 18 discrete sigma levels as the COLA AGCM. The fields were linearly interpolated to the T42 Gaussian grid, while the surface pressure was recalculated with the T42 resolution topography using the hydrostatic formula.

In preparing the base field for the RSM anomaly experiments (EXPT) the AGCM climatology of the nested variable from the AGCM is removed and replaced with the corresponding climatology from observation (in this case the NCEP reanalysis). It should be noted that the EXPTs were conducted for the years of 1996-97, 1997-98, and 1998-99 which categorically excludes the years from which the AGCM climatology was generated.

\section{Design of experiments}

The anomaly nesting procedure is tested for the season of January-February-March (JFM) of 1997, 1998, and 1999. A total of five ensemble members are run for each year. The initial conditions for the ensemble members of the AGCM are generated in the same manner as in Misra et al. (2003, hereafter M03). The initial conditions for the RSM are interpolated to its grid from the corresponding initial conditions of the AGCM. The start and end dates for both the AGCM and RSM integrations are identical: 0000 UTC 15 December and 1200 UTC 31 March of the following year. The first 15 days of the RSM integration are not analyzed in this study to account for spinup issues.

In all the model integrations the SST field is updated daily by linearly interpolating from the weekly Reynolds and Smith (1994) optimum interpolation SST dataset. The initial soil moisture fields are obtained from a 2-yr climatology of the Global Soil Wetness Project (Dirmeyer and Zeng 1999).

There are two sets of baseline experiments (referred to hereafter as control-A and control-B runs) which will be compared with the anomaly nesting integrations of the RSM (EXPT). Both sets of control runs cover the same time period (JFM of 1997, 1998, and 1999) as that of the current study. Control-A integrations refers to a set of RSM runs made with NCEP reanalysis as the base field which are described in Misra et al. (2002). It should be noted that in these integrations the base field of NCEP reanalysis was available on a Gaussian grid of triangular truncation at wavenumber 62. ControlB RSM integrations refers to the set of RSM runs made in M03. In this set of runs the RSM uses the base fields from the COLA AGCM, which is integrated at T42 triagular truncation spatial resolution. The RSM used in this study, and in control-A are not identical to the one used in control-B. This difference relates to the convective parameterization scheme adopted in the RSM. In control-B we noted that using the RAS convective parameterization scheme improved the simulation of the RSM near the lateral boundaries compared to the SAS scheme (Pan and Wu 1995). However, in this study we find that the SAS convective scheme reduced the errors near the lateral boundary conditions far more than the RAS scheme. This feature is present primarily because the NCEP reanalysis model utilizes SAS while the COLA AGCM uses the RAS convective schemes. As a result, in the sponge zone close to the lateral boundaries 


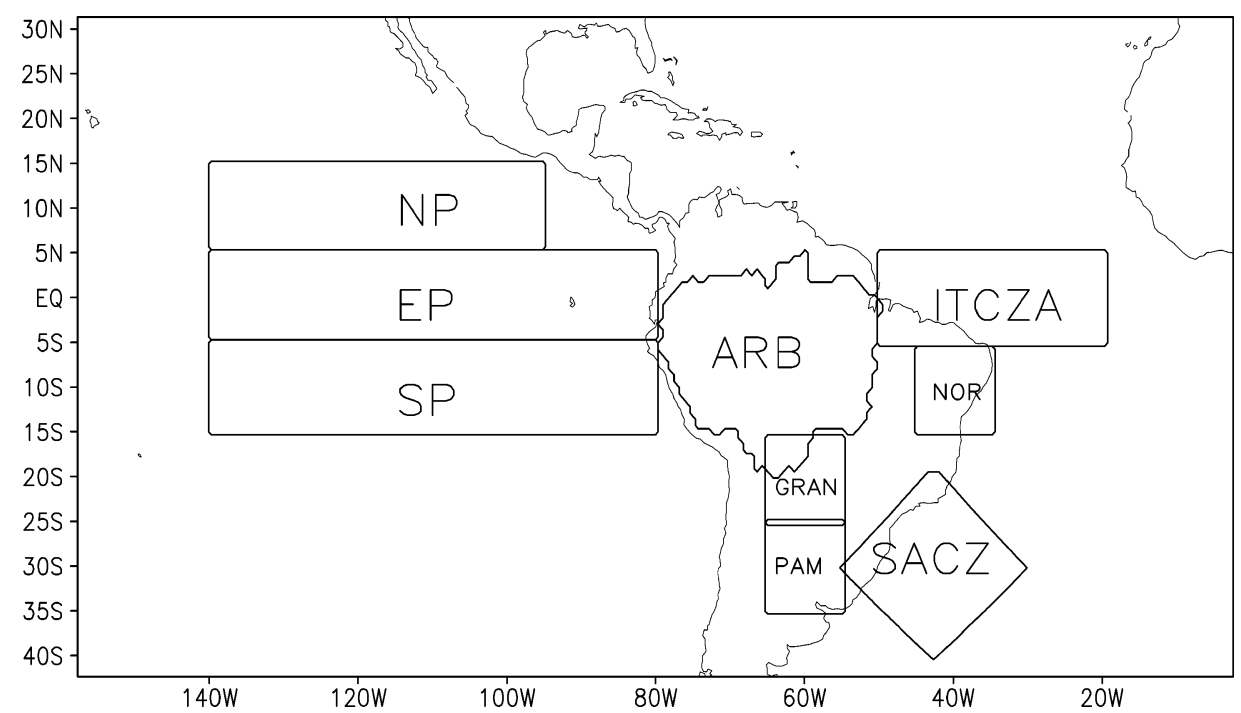

FIG. 1. Outline of the Amazon River basin (ARB), ITCZ over the Atlantic (ITCZA), Nordeste (NOR), South Atlantic convergence zone (SACZ), pampas region (PAM), Gran Chaco area (GRAN), South Pacific (SP), equatorial Pacific (EP), and North Pacific (NP) (borrowed from Misra et al. 2002).

a large amount of precipitation is generated initially which spreads into the interior of the domain by the end of the seasonal integration if the right convection scheme is not chosen. Another difference in the RSM used in control-A, control-B, and EXPT relates to the vertical discretization. In all the RSM runs forced by the COLA AGCM (control-B and EXPT) we use 18 sigma levels which are identical to the COLA AGCM vertical discretization. However, in control-A we adopted 28 sigma levels of the NCEP reanalysis model.

In theory, despite these model differences, control-A simulations represent an upper bound to the skill that can be attained through the anomaly nesting procedure adopted in this study. However, it is not necessary that control-A type (NCEP reanalysis driven) integrations should always represent the limit of regional climate predictability of anomaly nested regional models. It is plausible that some nested variables may have a better mean state described in the driving AGCM than the analysis climatology that is used to replace it.

\section{Results}

The focus of this study will be on the mean JFM seasonal precipitation and low-level circulation. In the following discussion we shall be presenting results of the seasonal mean from the ensemble mean computed over five ensemble members. This shall be followed with a discussion of the seasonal anomalies. For the sake of brevity we shall present some of the results averaged over the domains (as used in Misra et al. 2002) outlined in Fig. 1. To verify the model results, we use the Climate Prediction Center Merged Analysis Precipitation (CMAP) dataset (Xie and Arkin 1996) made available on $2.5^{\circ} \times 2.5^{\circ}$ latitude-longitude grid. Ob- served outgoing longwave radiation (OLR) fields based on Liebmann and Smith (1996) which are available daily on a $2.5^{\circ} \times 2.5^{\circ}$ latitude-longitude grid are also used for verification. It should be noted that in all validation efforts, the model output was interpolated to the observational grid.

\section{a. Total field}

It could be argued that the skill of simulating the anomalies would determine the efficacy of anomaly nesting as the mean field is prescribed by the lateral boundaries. However, it should be recognized that the RSM is continuously predicting the total field in the interior of the domain and therefore the mean field from the RSM is a nontrivial quantity in the anomaly nesting procedure.

\section{1) JFM SEASONAL PRECIPITATION}

In Fig. 2 we show the mean JFM seasonal precipitation from control-A, control-B, EXPT, NCEP reanalysis, and observations based on CMAP for 1997, 1998, and 1999. One of the major errors in the mean JFM precipitation patterns in control-B runs is the presence of an intense intertropical convergence zone (ITCZ) south of the equator in both Pacific and Atlantic Ocean basins which give rise to the split-ITCZ phenomenon. M03 suggested that this split-ITCZ phenomenon was a large-scale error forced on the RSM by the driving COLA AGCM through the lateral boundary conditions. This split-ITCZ phenomenon over the Pacific Ocean is also exhibited by the NCEP reanalysis and control-A RSM runs, especially in 1997 and 1999. In the EXPT runs the southern ITCZ is appreciably less intense and 

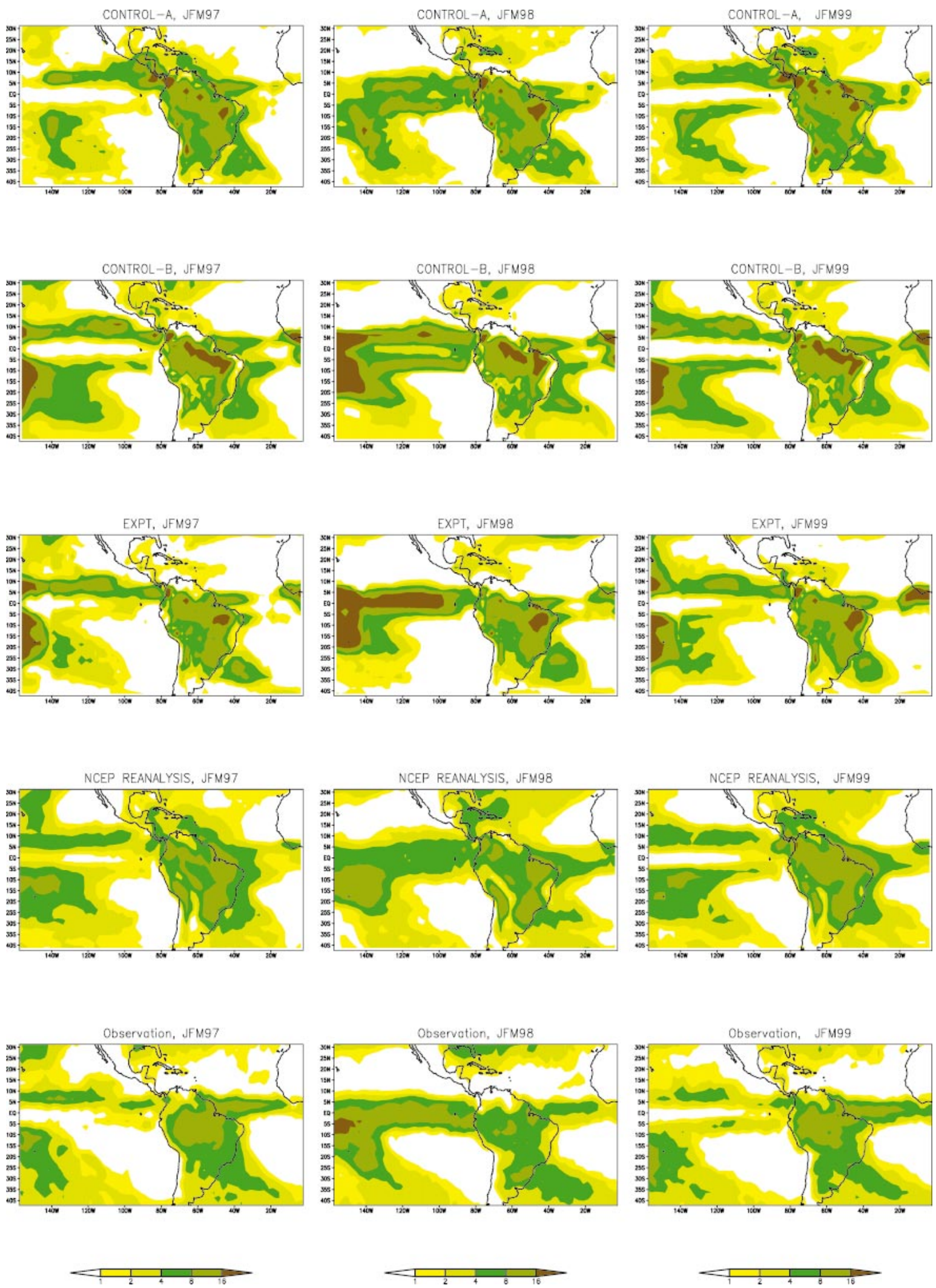

FIG. 2. Mean JFM precipitation in units of $m$ day $^{-1}$. 
1997
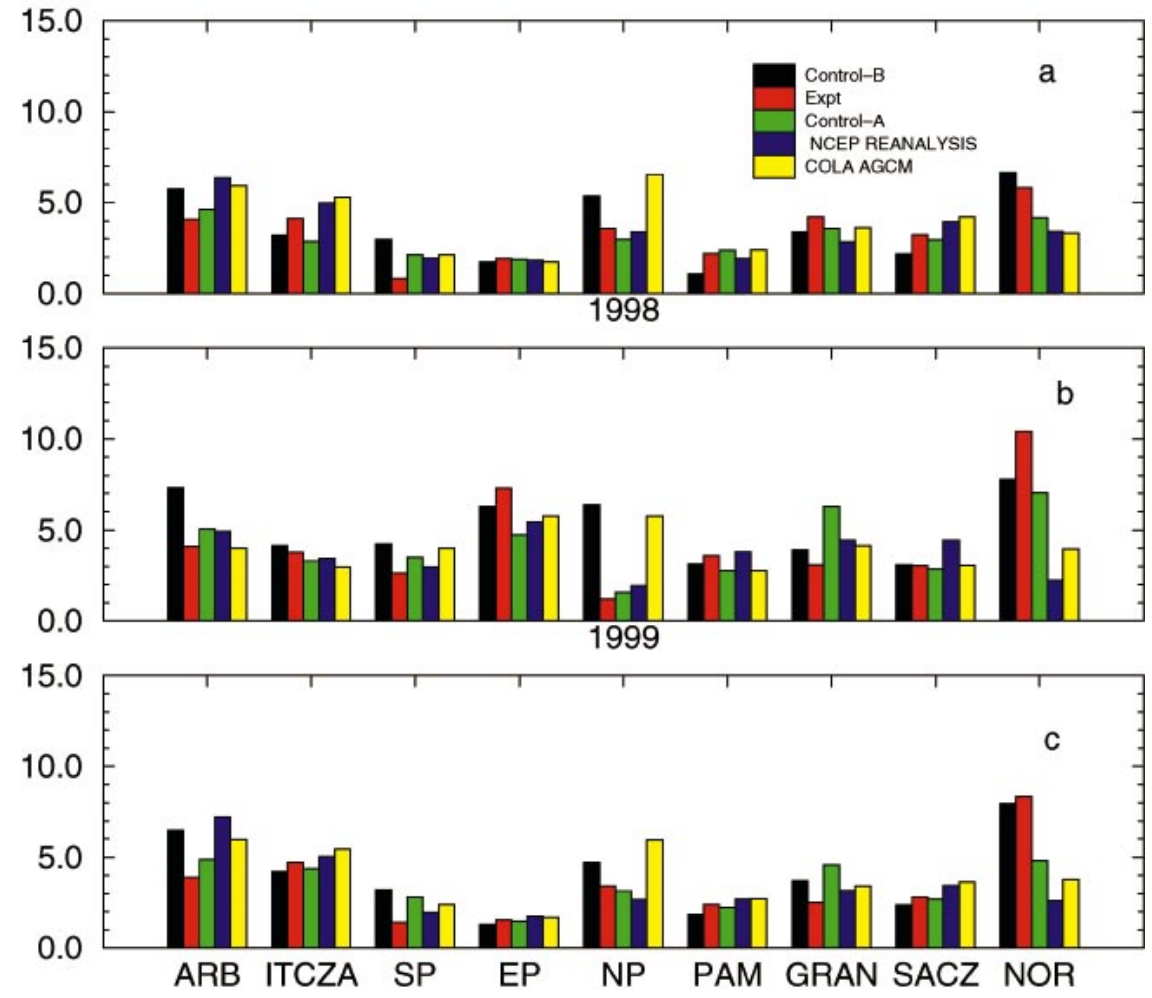

FIG. 3. The rmse for subdomains outlined in Fig. 1. Units are $\mathrm{mm} \mathrm{day}^{-1}$.

comparable to observations and to the control-A runs in 1997 and 1999. In JFM of 1998, during the strong warm El Niño-Southern Oscillation (ENSO) episode, the EXPT run displays a relatively more active ITCZ over the eastern Pacific Ocean, as in the observations. There is also a hint of the erroneous split-ITCZ phenomenon over the tropical Atlantic Ocean in all the model runs including the NCEP reanalysis. However, unlike that over the Pacific Ocean, the EXPT runs also display comparable intensity of precipitation just south of the equator over the tropical Atlantic Ocean. Another erroneous feature of the control-B integrations was the copious rainfall along the southeastern coast of Brazil in the southern Atlantic Ocean which has been significantly reduced in the EXPT simulations in all $3 \mathrm{yr}$. However, the EXPT run does deteriorate the simulation relative to control-B near the western edge of the regional domain in the South Pacific Ocean, and in the Nordeste region in all $3 \mathrm{yr}$.

The root-mean-square errors (rmse) of mean JFM precipitation for each of the domains shown in Fig. 1 are plotted in Fig. 3. The EXPT run shows a consistent improvement over control-B while being comparable to control-A integrations over ARB, SP, and NP. Over ITCZA, EP, PAM, GRAN, South Atlantic convergence zone (SACZ), and NOR the improvement in the EXPT runs are relatively inconsistent from one year to the other. As previously noted the COLA AGCM integra- tions show instances of lower rmse in precipitation than the NCEP reanalysis and some of the RSM runs. However, this does not necessarily translate to a superior simulation of precipitation in the control-B runs relative to the other RSM runs presented in this study. This could be a result of nonlinearities in downscaling the AGCM with large systematic errors.

\section{2) LOW-LEVEL CIRCULATION}

We have plotted the mean JFM 850-hPa circulation field in Fig. 4 for 1998 and 1999 from the various RSM integrations and NCEP reanalysis. For brevity we have not shown the fields from 1997. It is apparent from Fig. 4 that the low-level circulation in the EXPT runs compares more favorably with control-A simulations and NCEP reanalysis than do the control-B integrations. The subtropical flow over the southern Atlantic Ocean is more zonally oriented and extends into the subtropical plains of South America in the control-B integrations, which is distinctly different from the NCEP reanalysis. However, like the control-A runs the EXPT integrations conform more closely to the flow field depicted in the NCEP reanalysis. The northwesterly flow along the Altiplano plateau which develops into a low-level jet and constitutes a "moisture corridor" connecting the ARB and the Rio de La Plata basin during the mature phase of the South American summer monsoon (Mechoso 

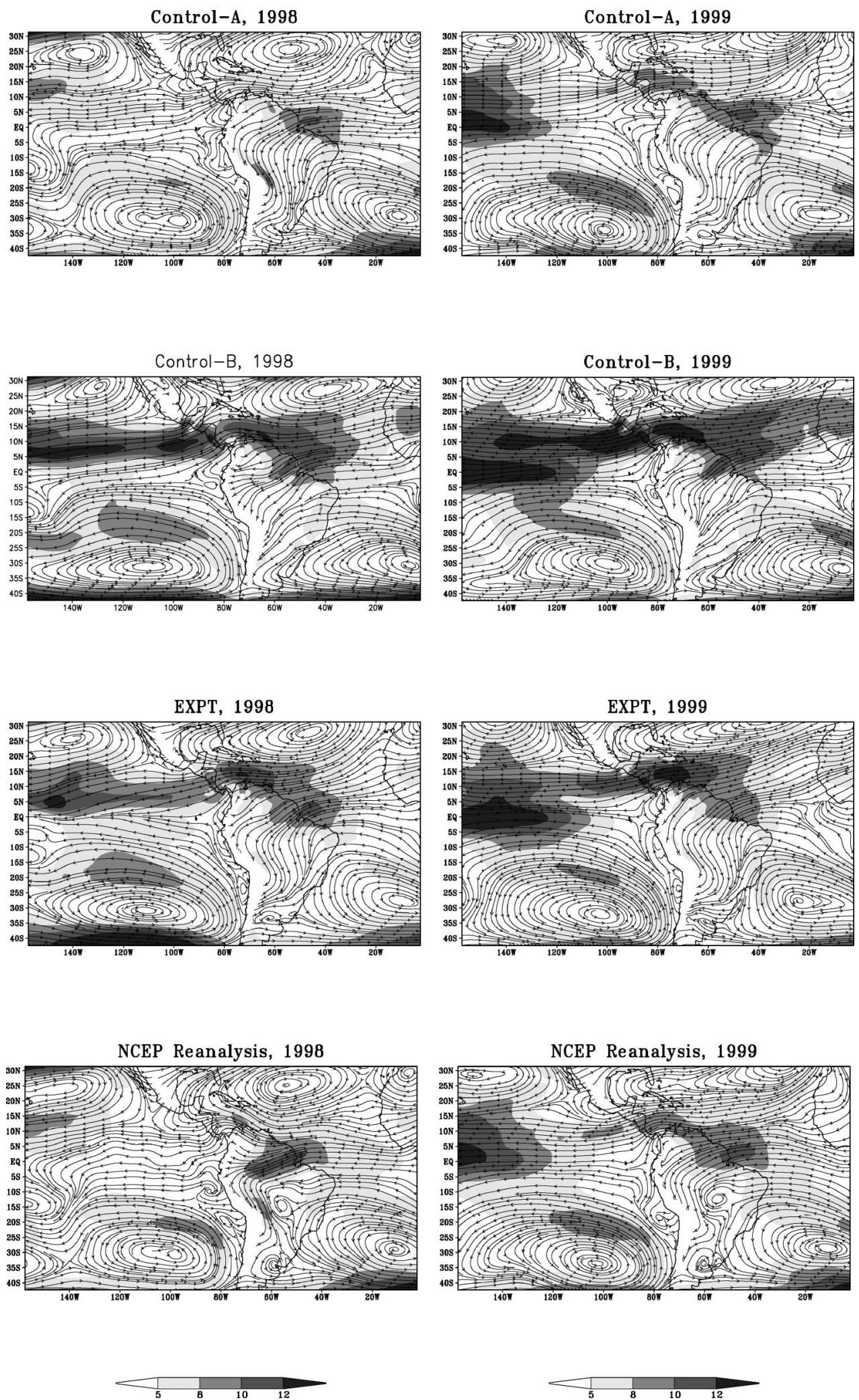

FIG. 4. Wind circulation at $850 \mathrm{hPa}$. Isotachs are shaded. Units are $\mathrm{m} \mathrm{s}^{-1}$. 
1997
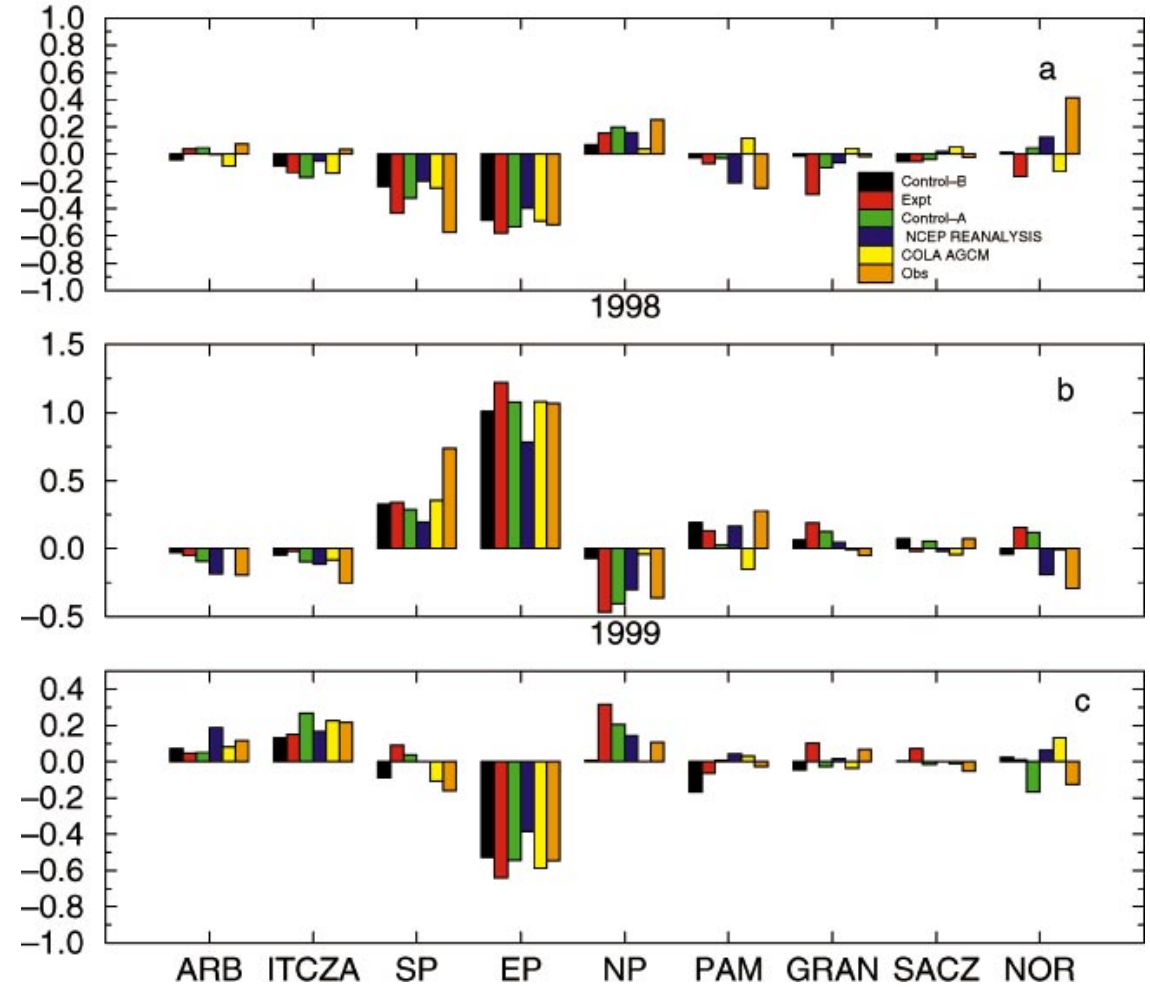

FIG. 5. The JFM precipitation anomalies normalized by the climatology of the respective subdomain outlined in Fig. 1 for (a) 1997, (b) 1998, and (c) 1999. Units are mm day ${ }^{-1}$.

2000) is totally absent in the control-B integrations, while it is simulated in the EXPT runs. Furthermore, the easterlies over the Tropics are relatively lower in magnitude in the EXPT runs than in control-B runs, which makes the former simulation closer to the NCEP reanalysis.

\section{b. Seasonal anomalies}

In Fig. 5 we have plotted the area average seasonal precipitation anomalies normalized by the climatology of the respective subdomain outlined in Fig. 1. It should be noted that the JFM precipitation climatology is computed from the $3 \mathrm{yr}$ of 1997, 1998, and 1999 to obtain Fig. 5. In Fig. 6 we have plotted the spatial correlations of these anomalies. From these two figures it is apparent that the EXPT produces a superior simulation of the precipitation anomalies over the control-B runs at least in three of the nine regions, namely, the ARB, the NP region, and the EP area. In other regions the improvement in the anomaly nesting is not observed consistently in all $3 \mathrm{yr}$. A limitation of this study is that we have small sample of years to verify these anomalies. However over the NOR region, the EXPT consistently shows anomalies of the opposite sign relative to the observations indicating a deterioration relative to control-B. Such a feature is also seen in anomalies from the control-
A experiment which leads us to believe that the bias in the NCEP climatology may have influence on the simulation over this region. The benefit of having improved low-level circulation in the EXPT is also reflected in the improvement in the precipitation anomalies over the PAM region which lies close to the exit region of the low-level jet along the eastern side of the Andes mountains. The anomalies from the NCEP reanalysis compares well with observations over most regions except over the GRAN region. The COLA AGCM generally displays a poor description of the precipitation anomalies over the area.

\section{c. Model internal variability}

There is a general tendency for the EXPT runs in this study to reduce (increase) the intrinsic variability over continental South America (oceans) relative to controlB integrations. As an example in Fig. 7 we have plotted the normalized standard deviation (NSD) following Misra et al. (2002) for precipitation from the control-B and EXPT runs. NSD is a measure of noise-to-signal ratio with values close to 0 (1) suggesting the dominance of signal (model noise). It is seen that over the ARB region and over eastern Brazil, the EXPT runs have reduced NSD relative to control-B. However, the model noise is more in the EXPT runs especially over the 
1997
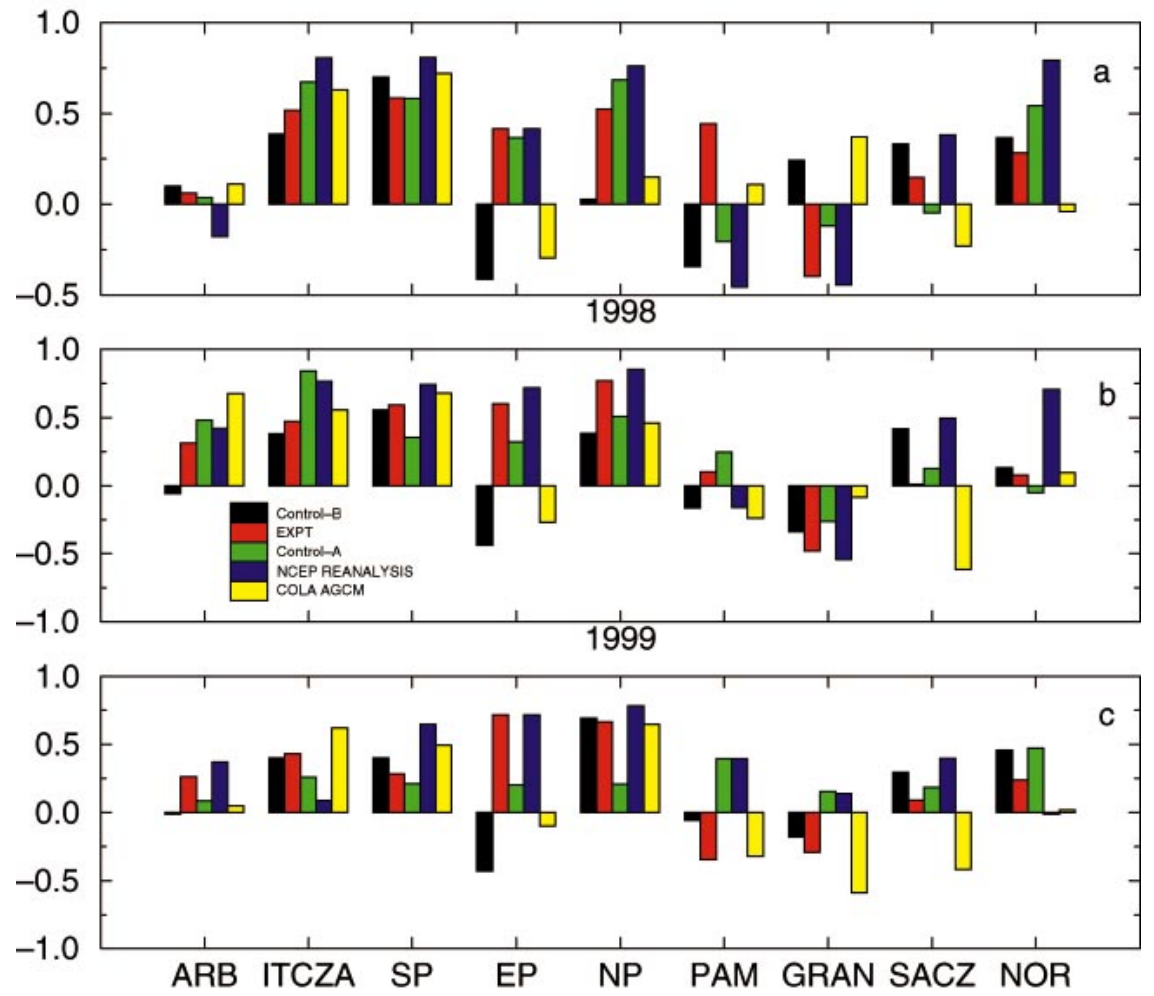

FIG. 6. The spatial correlation of the JFM precipitation anomalies for (a) 1997 , (b) 1998, and (c) 1999 for the subdomains outlined in Fig. 1 .

oceanic region of the SACZ and the equatorial Pacific Ocean. Such behavior is also observed in other model variables. This difference in the intrinsic variability is consistent from the difference in the simulated intraseasonal variability in the EXPT and control-B model integrations discussed in the following section.

\section{d. Intraseasonal variability}

Intraseasonal variability of the South American summer monsoon has been shown from the observational studies of Kousky and Kayano (1994), Liebmann et al. (1999), Paegle and Mo (1997), and Paegle et al. (2000). This intraseasonal variability bears a seesawlike pattern with centers of action over the SACZ and the subtropical plains of South America. It is observed that when the SACZ is weak, wet conditions prevail over the subtropical plains. This seesaw pattern has been identified as having a 30-40-day time scale and has been related to the Madden-Julian oscillation (MJO; Kousky and Kayano 1994; Paegle et al. 2000). More recently, Paegle et al. (2000), using singular spectrum analysis, have found that this seesaw pattern is also modulated at periods of 22-28 days. Buchmann et al. (1990) from his modeling study found periods of deficient rainfall over southern Brazil with enhanced rainfall over the Atlantic at time scales of 10 days. Lieb- mann et al. (1999) using observed OLR datasets examined submonthly variations and found that the ratio of 2-30- and 30-90-day variance is high (low) over the central Amazon (subtropical plains).

In Fig. 8 we show the variance of the OLR at 3-30day time scales from the model integrations and observations. A spectral bandpass filter is employed on daily mean OLR fields to obtain the anomalies from which the variance is computed. The regions of noticeable improvement in simulating this high-frequency variability by the EXPT runs over control integrations are over the equatorial Pacific Ocean, SACZ, and over the tropical Atlantic Ocean. In fact, the EXPT runs nearly restore the variability simulated at these time scales by the control-A integrations. Similarly, we show the 30-40-day variance of the OLR anomalies in Fig. 9. It is seen from this figure that the variance, especially over the SACZ region and the subtropical plains in EXPT runs, is comparable to the control-A integrations and observations. The control-B integrations show an erroneously reduced variance over SACZ and over the Tropics.

The fact that the interannual, intraseasonal, synoptic (3-30 day) variabilities, and the predictability of the RSM simulation through this anomaly nesting procedure are all different from the control-B integrations points to the importance of the deterministic mean state of the 

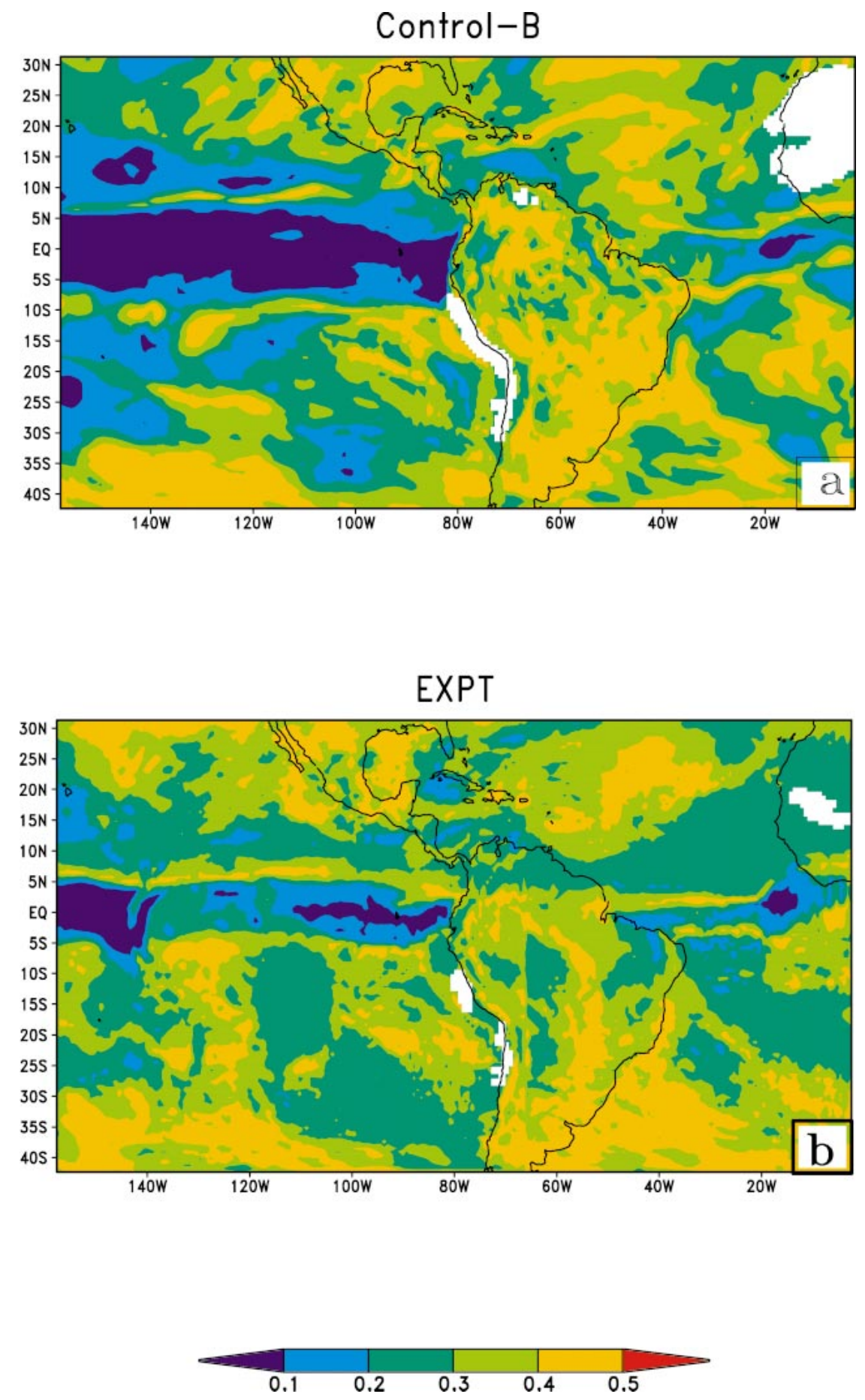

FIG. 7. The normalized standard deviation (see text) from (a) control-B and (b) EXPT model runs.

large scale. The scale interactions both in frequency and wavenumber domains seem to contribute significantly to the skill of the periodic behavior of the RSM simulations. Krishnamurti et al. (2003) show that the MJO signal in a coupled ocean-atmosphere integration can be amplified by way of nonlinear interactions between synoptic disturbances and a preexisting weak MJO that satisfy certain trigonometric selection rules. Kirtman et al. (2002) in comparing fully coupled ocean-atmosphere model integrations from the anomaly-coupled oceanatmosphere model runs (from which this concept of anomaly nesting for regional atmospheric model is borrowed) concluded that realistic ENSO variability is captured by simulating a correct mean state. 

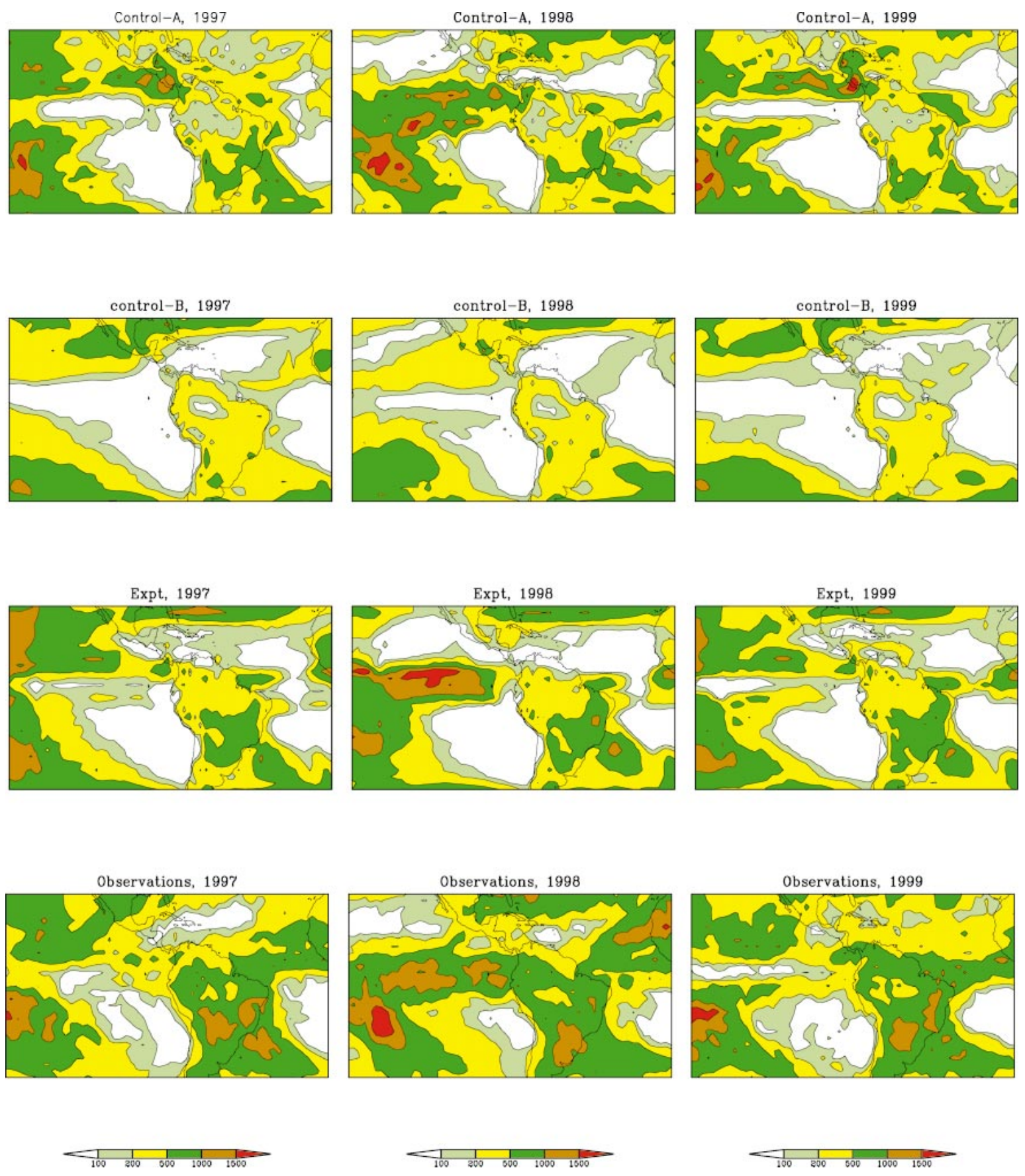

FIG. 8. Variance of 3-30-day OLR anomalies. Units are $\mathrm{W}^{2} \mathrm{~m}^{-4}$.

\section{Conclusions}

In this study we have proposed a new methodology to downscale AGCM seasonal climate simulations. It has the potential to stretch current limits of regional climate predictability at seasonal time scales. The premise of this methodology is based on the notion that the large-scale climate drift which influences the evolution of the regional climate can be eliminated by re- placing the driving AGCM's climatology with the observed climatology. However, the elimination of the drift is only partial in this study, as the observed climatology is made available from the NCEP reanalysis, which itself is model dependent in data-void regions and is also dependent on the adopted data assimilation scheme.

In this study we find that the anomaly nesting methodology significantly improves the austral summer sea- 

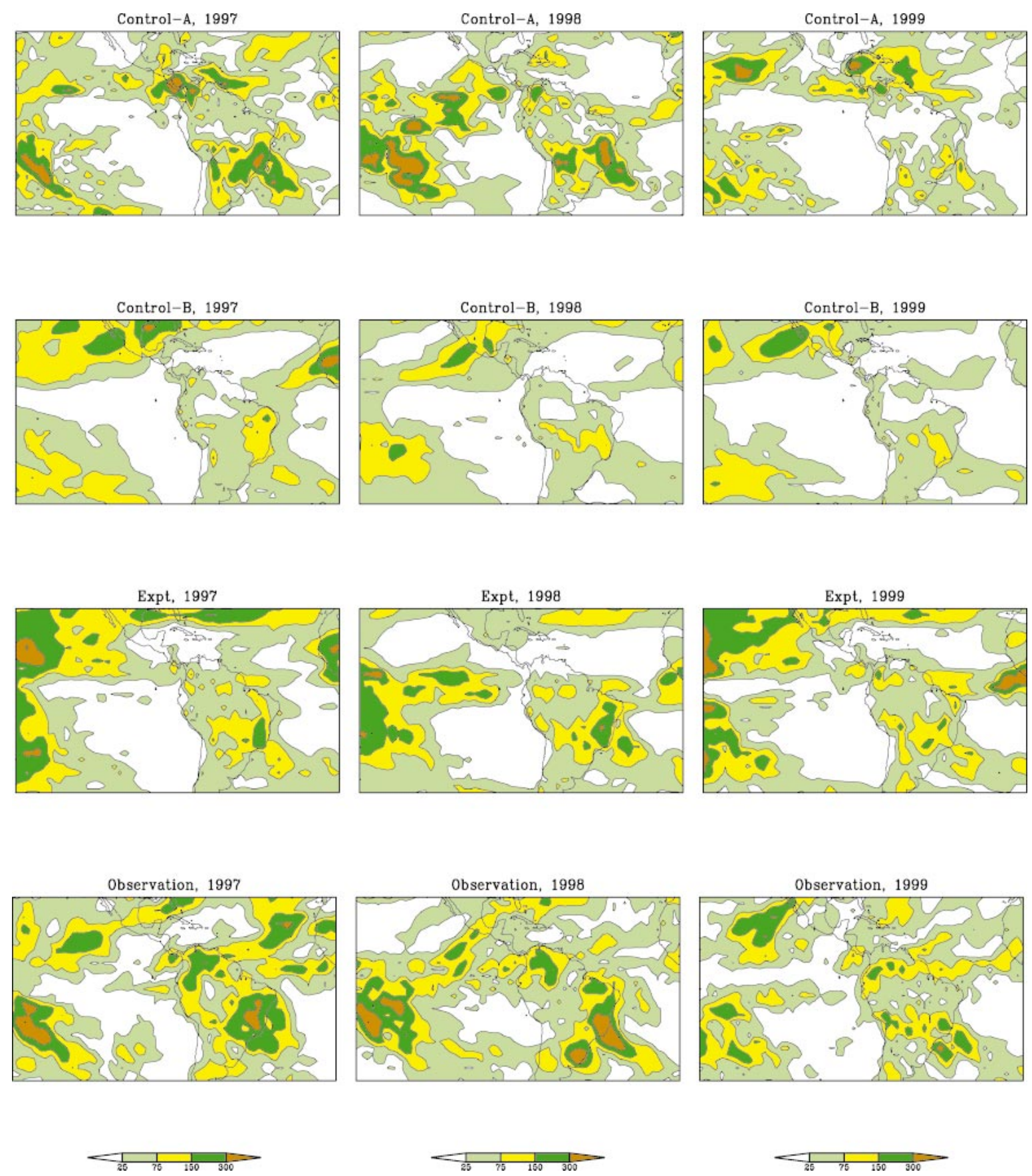

FIG. 9. Variance of 30-40-day OLR anomalies. Units are $\mathrm{W}^{2} \mathrm{~m}^{-4}$.

sonal precipitation over South America and the neighboring ocean basins relative to the conventional way of nesting RSM into the COLA AGCM. The pathological error of the split-ITCZ phenomenon, especially over the eastern Pacific Ocean, which is produced in the RSM simulations forced at the lateral boundaries by the COLA AGCM is significantly reduced in the anomaly nesting procedure. This further supports the notion that the split-ITCZ phenomenon is a large-scale error im- posed on the evolving regional climate of the RSM. The intraseasonal variability of the OLR anomalies is also appreciably improved in the EXPT runs which is related to the general increase in the model noise over the oceans in the anomaly nesting procedure. However, this study has been conducted over a small sample of years (three) which precludes the study of the anomaly nesting procedure to large-scale flow regimes associated, for example, with warm and cold ENSO phases. 
This anomaly nesting procedure also has the potential to lead to the understanding of the role of climate drift on the evolution of the regional climate in each of the nested variables separately. This is a subject of an ongoing set of experiments.

Acknowledgments. The authors wish to thank Drs. David Straus, Paul Dirmeyer, and two anonymous reviewers for their valuable comments on an earlier version of the manuscript. The authors would also like to acknowledge the use of interpolated OLR obtained from the NOAA-CIRES Climate Diagnostics Center, Boulder, Colorado, (from their Web site at http:// www.cdc.noaa.gov/). This study was supported by NSF Grant ATM9814295, NASA Grant NAG5-11656, NOAA Grant NA16GP2248, and a cooperative agreement from NOAA-NA17RJ1231. The views expressed herein are those of the authors and do not necessarily reflect the views of NOAA.

\section{REFERENCES}

Alpert, J. C., M. Kanamitsu, P. M. Caplan, J. G. Sela, G. H. White, and E. Kalnay, 1988: Mountain induced gravity wave drag parameterization in the NMC medium-range forecast model. Preprints, Eighth Conf. on Numerical Weather Prediction, Baltimore, MD, Amer. Meteor. Soc., 726-733.

Altshuler, E., M. Fennessy, J. Shukla, H. Juang, E. Rogers, K. Mitchell, and M. Kanamitsu, 2002: Seasonal simulations over North America with a GCM and three regional models. COLA Tech. Rep. 115, 60 pp.

Brankovic, C., and T. N. Palmer, 1997: Atmospheric seasonal predictability and estimates of ensemble size. Mon. Wea. Rev., 125, 859-874.

Buchmann, J., J. Paegleand, and L. E. Buja, 1990: The effect of tropical Atlantic heating anomalies upon GCM rain forecasts over the Americas. J. Climate, 3, 189-208.

Chou, M.-D., 1992: A solar radiation model for use in climate studies. J. Atmos. Sci., 49, 762-772.

Davies, R., 1982: Documentation of the solar radiation parameterization in the GLAS climate model. NASA Tech. Memo. 83961, $57 \mathrm{pp}$.

Denis, B., R. Laprise, D. Caya, and J. Cote, 2002: Downscaling ability of one-way nested regional climate models: The Big-Brother Experiment. Climate Dyn., 18, 627-646.

DeWitt, D. G., and E. K. Schneider, 1997: The earth radiation budget as simulated by the COLA GCM. COLA Rep. 35, 39 pp. [Available from COLA, 4041 Powder Mill Rd., Suite 302, Calverton, MD 20705.]

Dirmeyer, P. A., and F. J. Zeng, 1997: A two dimensional implementation of the Simple Biosphere $(\mathrm{SiB})$ model. COLA Tech. Rep. 48, 30 pp. [Available from Center for Ocean-Land-Atmosphere Studies, 4041 Powder Mill Road, Suite 302, Calverton, MD 20705.]

— , and — 1999: An update to the distribution and treatmen of vegetation and soil properties in SSiB. COLA Tech. Rep. 78, 25 pp. [Available from Center for Ocean-Land-Atmosphere Studies, 4041 Powder Mill Road, Suite 302, Calverton, MD 20705.]

Druyan, L. M., M. Fulakeza, and L. Patric, 2002: Dynamic downscaling of seasonal climate predictions over Brazil. J. Climate, $15,84-117$

Fels, S. B., and M. D. Schwarzkopf, 1975: The simplified exchange approximation: A new method for radiative transfer calculations. J. Atmos. Sci., 32, 2265-2297.
Fennessy, M. J., and Coauthors, 1994: The simulated Indian monsoon: A GCM sensitivity study. J. Climate, 7, 33-43.

Harshvardhan, R. Davies, D. A. Randall, and T. G. Corsetti, 1987: A fast radiation parameterization for atmospheric circulation models. J. Geophy. Res., 92 (D1), 1009-1016.

Hong, S.-Y., and H.-L. Pan, 1996: Nonlocal boundary layer vertical diffusion in a medium-range forecast model. Mon. Wea. Rev., 124, 2322-2339.

Jones, R. G., J. M. Murphy, and M. Noguer, 1995: Simulations of climate change over Europe using a nested regional climate model. I: Assessment of control climate, including sensitivity to location of lateral boundaries. Quart. J. Roy. Meteor. Soc., 121, 1413-1449.

Juang, H.-M., and M. Kanamitsu, 1994: The NMC nested regional spectral model. Mon. Wea. Rev., 122, 3-26.

- S.-Y. Hong, and M. Kanamitsu, 1997: The NCEP regional spectral model: An update. Bull. Amer. Meteor. Soc., 78, 21252143.

Kiehl, J. T., J. J. Hack, G. Bonan, B. A. Boville, D. L. Williamson, and P. J. Rasch, 1998: The National Center for Atmospheric Research Community Climate Model: CCM3. J. Climate, 11, 1131-1149.

Kirtman, B. P., Y. Fan, and E. K. Schneider, 2002: The COLA global coupled and anomaly coupled ocean-atmosphere GCM. J. Climate, 15, 2301-2320.

Kousky, V. E., and M. T. Kayano, 1994: Principal modes of outgoing longwave radiation and 250-mb circulation for the South American sector. J. Climate, 7, 1131-1143.

Krishnamurti, T. N., D. N. Chakraborty, N. Cubukcu, L. Stefanova, and T. S. V. Vijaya Kumar, 2003: A mechanism of the MJO based on interactions in the frequency domain. Quart. J. Roy. Meteor. Soc., 129, 2559-2590.

Liebmann, B., and C. A. Smith, 1996: Description of a complete (interpolated) outgoing longwave radiation dataset. Bull. Amer. Meteor. Soc., 77, 1275-1277.

_ , G. N. Kiladis, J. A. Marengo, T. Ambrizzi, and J. D. Glick, 1999: Submonthly convective variability over South America and the South Atlantic convergence zone. J. Climate, 12, 18771891.

Mechoso, C., 2000: Introduction to VAMOS. CLIVAR Exchanges, 5, 4-6.

Mellor, G. L., and T. Yamada, 1982: Development of a turbulence closure model for geophysical fluid processes. Rev. Geophys. Space Phys., 20, 851-875.

Misra, V., P. A. Dirmeyer, and B. P. Kirtman, 2002: A comparative study of two land surface schemes in regional climate integrations over South America. J. Geophys. Res., 107, 8080, doi:10.1029/2001JD001284

,,- and -2003 : Dynamic downscaling of regional climate over South America. J. Climate, 16, 103-117.

Moorthi, S., and M. J. Suarez, 1992: Relaxed Arakawa-Schubert: A parameterization of moist convection for general circulation models. Mon. Wea. Rev., 120, 978-1002.

Noguer, M., R. G. Jones, and J. Murphy, 1998: Sources of systematic errors in the climatology of a nested regional climate model (RCM) over Europe. Climate Dyn., 14, 691-712.

Paegle, J. N., and K. C. Mo, 1997: Alternationg wet and dry conditions over South America during summer. Mon. Wea. Rev., 125, 279-291.

- L. A. Byerle, and K. C. Mo, 2000: Intraseasonal modulation of South American summer precipitation. Mon. Wea. Rev., 128, 837-850.

Pan, H.-L., and W.-S. Wu, 1995: Implementing a mass flux convective parameterization package for the NMC medium-range forecast model. NMC Office Note 409, $40 \mathrm{pp}$. [Available from NOAA/ NWS/NCEP, Environmental Modeling Center, WWB, Room 207, Washington, DC 20233.]

Pan, Z., J. H. Christensen, R. W. Arritt, W. J. Gutowski, E. S. Takle, and F. Otieno, 2001: Evaluation of uncertainties in regional climate change simulations. J. Geophys. Res., 106, 17 735-17 752. 
Reynolds, R. W., and T. M. Smith, 1994: Improved global sea surface temperature analyses using optimum interpolation. J. Climate, 7, 929-948.

Risbey, J. S., and P. H. Stone, 1996: A case study of the adequacy of GCM simulations for input to regional climate change assessments. J. Climate, 9, 1441-1467.

Roads, J. O., and S.-C. Chen, 2000: Surface water and energy budgets in the NCEP regional spectral model. J. Geophys. Res., 105, 29 539-29 550.

- _ - _ and M. Kanamitsu, 2003: U.S. regional climate simulations and seasonal forecasts. J. Geophys. Res., 108, 8606, doi:10.1029/2002JO002232.

Takle, E. S., and Coauthors, 1999: Project to intercompare regional climate simulation (PIRCS): Description and initial results. $J$. Geophys. Res., 104, 19 443-19 461.

Tiedtke, M., 1984: The effect of penetrative cumulus convection on the large-scale flow in a general circulation model. Beitr. Phys. Atmos., 57, 216-239.

Xie, P., and P. Arkin, 1996: Analyses of global monthly precipitation using guage observations, satellite estimates, and numerical model predictions. J. Climate, 9, 840-858.

Xue, Y.-K., P. J. Sellers, J. L. Kinter, and J. Shukla, 1991: A simplified biosphere model for global climate studies. J. Climate, 4, 345-364. F. J. Zeng, and C. A. Schlosser, 1996: SSiB and its sensitivity to soil properties: A case study using HAPEX-Mobilhy data. Global Planet. Change, 13, 183-194. 